Review

\title{
Chemical durability of high translucent dental zirconia
}

\author{
Seiji BAN \\ Department of Dental Materials Science, School of Dentistry, Aichi Gakuin University, Nagoya, Japan \\ Corresponding author, Seiji BAN; E-mail: sban@g.agu.ac.jp
}

\begin{abstract}
This review describes low temperature degradation (LTD), discoloration, and erosion of high translucent dental zirconia and discusses its chemical durability in comparison with other CAD/CAM materials. The LTD of zirconia strongly depended on the firing temperature, yttria content, surface treatment, and heat treatment. Glass ceramics for CAD/CAM were remarkably etched in a lactic acid at $60^{\circ} \mathrm{C}, \mathrm{KOH}$ solution at $60^{\circ} \mathrm{C}$, and saline solution at $90^{\circ} \mathrm{C}$, whereas zirconia showed no changes in these solutions. Glass ceramics and hybrid resins for $\mathrm{CAD} / \mathrm{CAM}$ showed significant discoloration in a red wine and rhodamine $\mathrm{B}$ solution at $37^{\circ} \mathrm{C}$, whereas zirconia showed no discolorations in either solution. It was concluded that high translucent dental zirconia has the highest chemical durability among dental CAD/CAM materials.
\end{abstract}

Keywords: Zirconia, Dentistry, Low temperature degradation, Chemical durability, Discoloration

\section{INTRODUCTION}

Zirconia was introduced to dentistry as a CAD/CAM material in $1998^{1,2)}$ because it has superior mechanical properties $^{2-6)}$ and useful physical properties ${ }^{7-9}$. Nowadays, zirconia restoration is not a special technique utilizing the CAD/CAM system, and is widely used in dental clinics as a general procedure. The composition of dental zirconia dramatically changed in the past two decades ${ }^{10)}$. Initially, conventional tetragonal zirconia (TZP) stabilized with $3 \mathrm{~mol} \%$ of yttria with about 0.25 wt $\%$ of alumina (3Y-HA) was mainly used as a core ceramic instead of metal. It is usually veneered with a feldspathic porcelain because 3Y-HA has an insufficient translucency. However, the strength of the veneering porcelain is not sufficient to act as a dental restorative, especially for posterior teeth. Clinical failure has been reported to be mostly chipping of porcelain ${ }^{11-13)}$. In 2011, high translucent TZP stabilized with $3 \mathrm{~mol} \%$ of yttria with less than $0.05 \mathrm{wt} \%$ of alumina (3Y) was introduced to dentistry. $3 \mathrm{Y}$ is mainly used as monolithic zirconia posterior crown because the surface of the zirconia prosthesis is not required to be covered with feldspathic porcelain owing to its high translucency. Thus, the possibility of porcelain chipping is greatly reduced. Furthermore, the amount of tooth removal is reduced because it is not necessary to prepare veneering space with porcelain. In 2014, partially stabilized zirconia (PSZ) stabilized with about $5 \mathrm{~mol} \%$ of yttria (5Y) was applied to dentistry. $5 \mathrm{Y}$ is mainly used as a monolithic zirconia anterior crown because it has higher translucency owing to the higher fraction of the cubic phase and lower fraction of the tetragonal phase of zirconia ${ }^{9}$. However, the mechanical strength of $5 \mathrm{Y}$ is almost half that of $3 \mathrm{Y}$ due to the reduction in the fraction of tetragonal zirconia; tetragonal zirconia

Color figures can be viewed in the online issue, which is available at J-STAGE.

Received Apr 14, 2019: Accepted Jun 4, 2019

doi:10.4012/dmj.2019-109 JOI JST.JSTAGE/dmj/2019-109 generates the stress-induced transformation resulting in the strengthening of the mechanical properties. In 2016, PSZ stabilized with about $4 \mathrm{~mol} \%$ of yttria (4Y) was introduced as an intermediate material between $3 \mathrm{Y}$ and 5Y. In 2017, high translucent PSZ stabilized with about $6 \mathrm{~mol} \%$ of yttria (6Y) was announced. At the same time, a half-sintered body of pre-shade was provided, making color tone adjustment easier. In addition, a multi-layer type with several pre-shade layers was released. By using this, an aesthetic monolithic zirconia crown can be produced with minimal work. Furthermore, from 2016 to 2018, not only shade-lamination, but also a mixed composition-lamination type consisting of TZP and PSZ has been provided ${ }^{14}$. Various dental zirconia became commercially available from various companies one after another, and the zirconia currently available in dentistry are classified into ten types ${ }^{10)}$.

Because the mechanical characteristics are considerably different depending on type, when designing a restoration, it is necessary to pay attention to the minimum wall thickness and the cross-sectional area of the connecting part for each prosthesis. Despite differences in yttria content and crystal phases, there are no large differences in any type of zirconia in the elastic modulus (about $200 \mathrm{GPa}$ ), Vickers hardness $(1,300 \mathrm{GPa})$, or the coefficient of thermal expansion (about $\left.10 \times 10^{-6} / \mathrm{K}\right)^{10}$. This suggests that these properties are strongly dependent on the bonding strength of $\mathrm{Zr}$ and $\mathrm{O}$, and independent of the fraction of the crystal phase. Therefore, chemical properties such as dissolution resistance are almost the same. However, among the chemical properties, low temperature degradation (LTD) strongly depends on the crystal phase and changes drastically with the yttria content. In addition, the LTD of high translucent zirconia is a concern because the surface of a monolithic zirconia crown is directly exposed to the oral cavity. In this review, the chemical durability of high translucent zirconia are evaluated in comparison 
with other esthetic dental CAD/CAM materials, through the properties of LTD, discoloration, and chemical etching.

\section{LOW TEMPERATURE DEGRADATION (LTD)}

\section{Degradation of zirconia}

Among the chemical properties of zirconia, LTD is frequently pointed out as being a type of degradation due to phase transformation in the presence of moisture. Experimental observations on aging have been summarized by Yoshimura et al. ${ }^{15}$. Because the temperature range of $200-300^{\circ} \mathrm{C}$ is relatively low among engineering materials, the term "low temperature degradation" is used for this type of degradation of zirconia. Because the temperature range of $200-300^{\circ} \mathrm{C}$ is quite high for zirconia materials such as biomaterials in the human body, it was assumed that LTD on them did not occur. However, some zirconia balls in total hip joints fractured within a short period between 1998 and $2000^{16,17)}$. It was concluded that the failure was due to LTD after an inattentive firing process ${ }^{18}$. This meant that the LTD of zirconia could occur at body temperature if unusual firing conditions have been employed.

In the case of high translucent dental zirconia, which is directly exposed to the oral cavity, there is concern that it may not survive in the oral cavity for a long period due to LTD. However, this review explains that such concerns are baseless.

Various theories promise that TZP degradation by water is caused by oxygen defects. The scenario often proposed for the LTD of tetragonal $\mathrm{ZrO}_{2}$ consists of the following steps ${ }^{19)}$ :

(i) chemical adsorption of $\mathrm{H}_{2} \mathrm{O}$ on the $\mathrm{ZrO}_{2}$ surface,

(ii) reaction of $\mathrm{H}_{2} \mathrm{O}$ with $\mathrm{O}_{2}$ on the $\mathrm{ZrO}_{2}$ surface to form a hydroxyl ion $(\mathrm{OH})$,

(iii) penetration of $\mathrm{OH}$ into the inner part by grain boundary diffusion,

(iv) filling of oxygen vacancies within the grains by $\mathrm{OH}$ ions, followed by the formation of proton defects,

(v) occurrence of a tetragonal to monoclinic transformation when the oxygen vacancy concentration is reduced to the extent that the tetragonal phase is no longer stable.

Thus, the crystal lattice volume increases due to the phase transformation from tetragonal to monoclinic, which results in micro- and macro-cracking. Many procedures are required in the production of a monolithic zirconia crown using the CAD/CAM system ${ }^{20)}$. First, large products are milled from a pre-sintered block and fired at $1,350-1,600^{\circ} \mathrm{C}$. After final firing, the sizes of the products lineally decrease by about $18-20 \%$ due to sintering shrinkage ${ }^{10)}$. The outer surfaces of the crown are usually mirror polished and sometimes heat-treated. After being cemented in the oral sites, the surfaces of the monolithic zirconia crowns are exposed in the oral cavity in which they contact to food and drink, both hot and cool, and endure the stress due to occlusion with various foods and antagonists. Thus, various factors affect the LTD of zirconia for dental treatment. Each factor is explained below.

\section{Evaluation of LTD}

LTD is generally evaluated through the monoclinic zirconia fraction of the specimen. The crystal phase of zirconia can be easily quantitatively analyzed by X-ray diffractometry. Usually, X-ray diffraction curves are measured from $26^{\circ}$ to $33^{\circ}$ in $2 \theta$. The peaks around $28.2^{\circ}$ and $31.4^{\circ}$ in $2 \theta$ are assigned as $(-111)$ and (111) of monoclinic zirconia, and the peak around $29.8^{\circ}$ in $2 \theta$ is assigned as (101) of tetragonal zirconia. Using these peaks, the monoclinic fraction can be assessed according to the following equation, proposed by Toraya et al. ${ }^{21)}$ :

$$
f=1.311 X m /(1+0.311 X m) \text {. }
$$

The integrated intensity ratio, $\mathrm{Xm}$, was calculated using the Garvie and Nicholson method ${ }^{22}$ as follows:

$$
X m=[\operatorname{Im}(-111)+\operatorname{Im}(111)] /[\operatorname{Im}(-111)+\operatorname{Im}(111)+\operatorname{It}(101)],
$$

where $\operatorname{Im}(\mathrm{h} \mathrm{k} \mathrm{l})$ is the area of the peak associated with the plane $(\mathrm{h} \mathrm{k} \mathrm{l})$ of the monoclinic phase and $I t(\mathrm{~h} \mathrm{k} \mathrm{l})$ is the area of the peak associated with the plane (h k l) of the tetragonal phase.

Effect of storage temperature and theoretical analysis Phase transformation due to LTD is the largest at 200$300^{\circ} \mathrm{C}$ on the surface of the zirconia. This temperature range is referred to as LTD because it falls in the category of a low temperature in the testing condition of industrial parts, but it is too high for evaluating dental restorative material. The LTD of zirconia used in medical and dental treatment should be evaluated at $37^{\circ} \mathrm{C}$; however, an accelerated test is usually employed because a quite long test period at $37^{\circ} \mathrm{C}$ is required because of the significantly low change rate. The accelerated aging test specified in ISO 13356 "Implants for surgery - Ceramic materials based on yttria-stabilized tetragonal zirconia (Y-TZP)" is as follows: the specimens are placed in a suitable autoclave and exposed to steam at $134 \pm 2^{\circ} \mathrm{C}$ under a pressure of $2 \mathrm{bar}$ for $5 \mathrm{~h}$. The maximum amount of monoclinic phase after accelerated aging should be less than $25 \%$.

The accelerated test for dental zirconia is not specified in any ISO standard; therefore, the LTD test for dental zirconia is usually undertaken in an autoclave at $134^{\circ} \mathrm{C}$ with steam under 2 bar according to ISO 13356, and the transformed amount of monoclinic zirconia is determined by X-ray diffractometry as mentioned above.

To ascertain the change at a lower temperature, we measured X-ray diffraction curves of six kinds of dental zirconia stored at $134,121,105,90,60$, and $37^{\circ} \mathrm{C}$ for up to 5 years. Cercon ht (Dentsply Sirona, Charlotte, NC, USA), Zenostar (Wieland, Ulm, Germany), inCoris TZI (Dentsply Sirona), and Upcera (Shenzhen Upcera Dental Technology, Shenzen, China) are classified 
as high translucent TZPs (3Y), Katana HT (Kuraray Noritake Dental, Tokyo, Japan) is classified as a high strength PSZ (4Y), and Nanozr (Yamakin, Osaka, Japan) is a nanocomposite consisting of ceria-stabilized TZP and alumina, and was used for comparison. The results at 134,121 , and $105^{\circ} \mathrm{C}$ were obtained after storage in an autoclave (SN200, Yamato Kagaku, Tokyo, Japan), and the results at 90,60 , and $37^{\circ} \mathrm{C}$ were obtained after soaking in physiological saline solution maintained at each temperature.

X-ray diffraction patterns of polished high translucent zirconia (Cercon $\mathrm{ht}$ ) in an autoclave at $134^{\circ} \mathrm{C}$ shows slight peaks due to the formation of the monoclinic phase at $5 \mathrm{~h}$ and a larger peak intensity of $m(-111)$ than
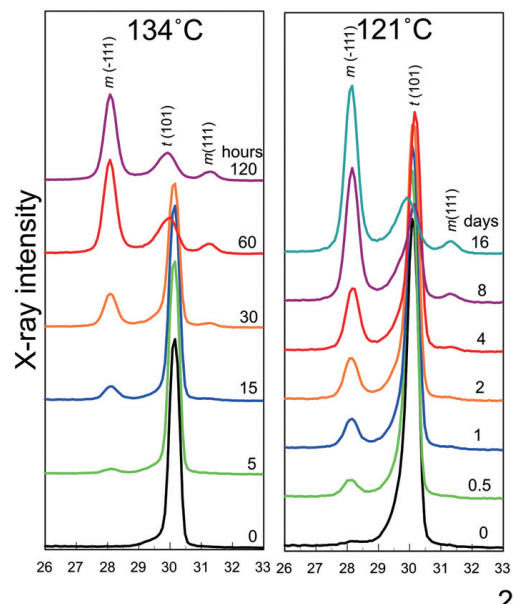

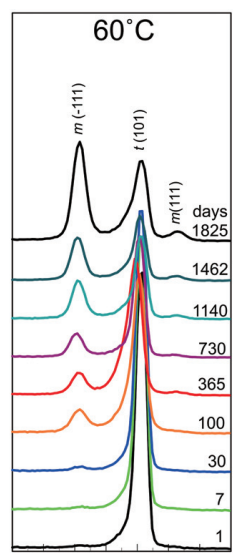

$2 \theta^{\circ}$

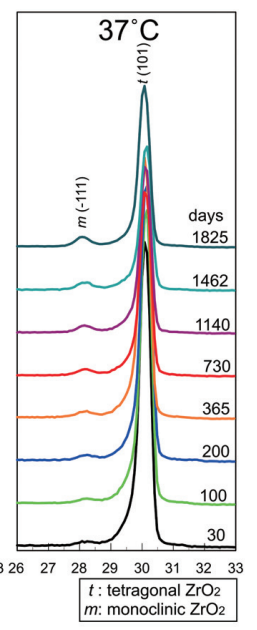

Fig. 1 X-ray diffraction patterns of polished Cercon ht (3Y) after storage at $134,121,60$, and $37^{\circ} \mathrm{C}$ up to 5 years.
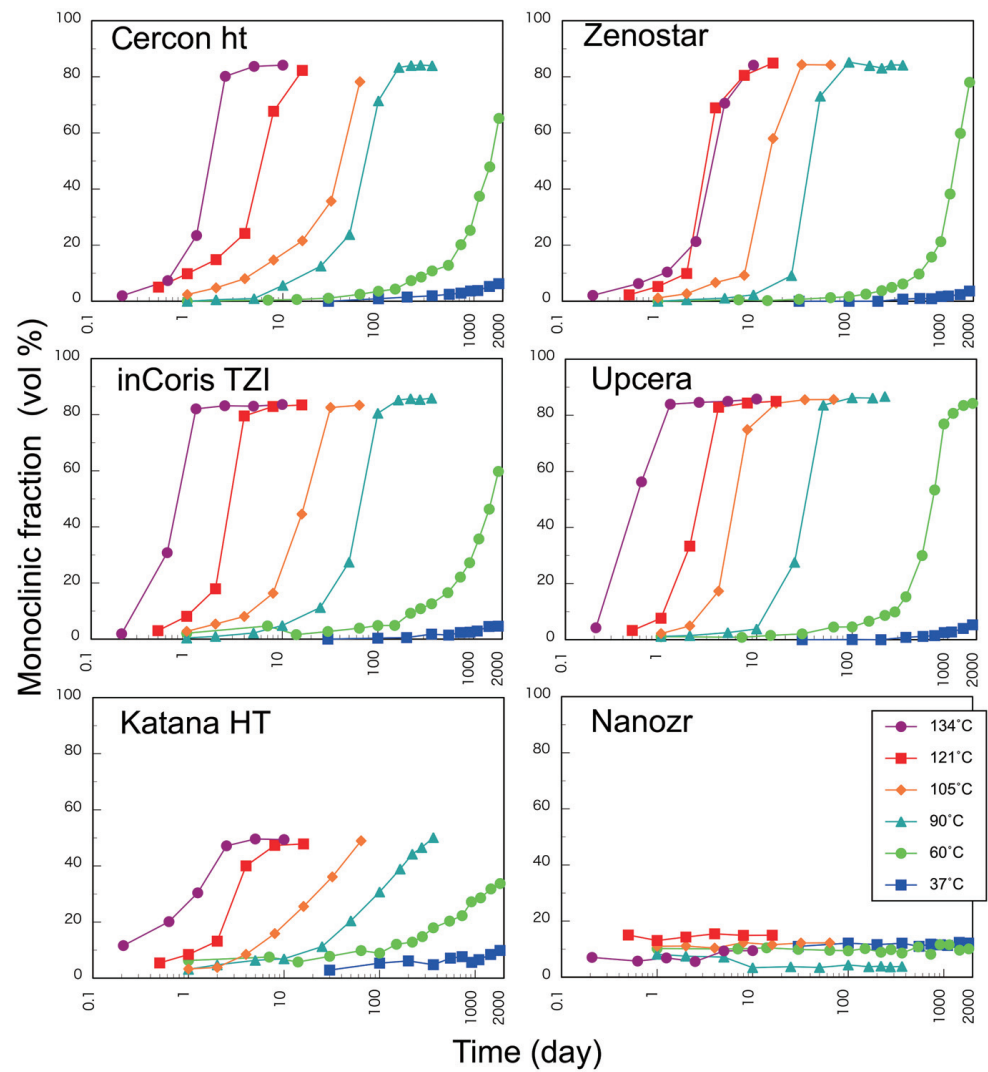

Fig. 2 Monoclinic content of six kinds of polished dental zirconia after storage at $134,121,105,90,60$, and $37^{\circ} \mathrm{C}$ up to 5 years. 
$t(101)$ at $60 \mathrm{~h}$ (Fig. 1). The peak intensity of $m(-111)$ is larger than $t(101)$ at 6 days at $121^{\circ} \mathrm{C}$, and 1,825 days (=5 years) at $60^{\circ} \mathrm{C}$. The peak of monoclinic phase is still small even after 1,825 days $\left(=5\right.$ years) at $37^{\circ} \mathrm{C}$.

From these X-ray diffraction curves, the fractions of monoclinic zirconia were derived for six kinds of polished zirconia at $134,121,105,90,60$, and $37^{\circ} \mathrm{C}$ up to 5 years (Fig. 2).

Four kinds of $3 \mathrm{Y}$ (Cercon ht, Zenostar, inCoris TZI, and Upcera) show nearly the same changes. At $134^{\circ} \mathrm{C}$, the monoclinic fractions were nearly saturated to $80-$ $83 \%$ at $30-60 \mathrm{~h}$. With a decreasing storage temperature, the rates of transformation decreased. Although the transformation rates of Katana HT (4Y) were nearly the same as those of $3 \mathrm{Y}$, their saturated values were almost $50 \%$. It seems to depend on whether the fraction of the tetragonal phase in $4 \mathrm{Y}$ is lower than that in $3 \mathrm{Y}$ and whether the stability of the tetragonal phase is improved by the higher yttria content. However, Nanozr showed no transformations at any temperature. It is concluded that Nanozr is quite stable because TZP is sufficiently stabilized by ceria.

The monoclinic fraction change against the logarithmic elapsed time appears as an S-shape curve. This reaction follows the law of Mehl-AvramiJohnson ${ }^{23)}$.

$$
f=1-\exp \left[-(b \cdot t)^{n}\right]
$$

where $f$ is the monoclinic fraction transformed from the tetragonal phase, $t$ is the time of exposure to moisture or soaking in water media, and $b$ and $n$ are constants that depend on temperature.

The apparent activation energy $Q$ was calculated by an Arrhenius type equation:

$$
b=b_{o} \cdot \exp (-Q / R T)
$$

where $b$ is the reaction rate, $b_{0}$ is a material constant, $R$ is the gas constant $[8.318 \mathrm{~J} /(\mathrm{mol} \cdot \mathrm{K})]$ and $T$ is the absolute temperature. The slope of $\ln b$, plotted in the function of the reciprocal of temperature, gives the apparent activation energy value for phase transformation. However, no ideal S-curves were obtained for any result because the numbers of plot points were not enough to fit an S-curve in a fast transformation, such as the changes at $134^{\circ} \mathrm{C}$, and/or in the slow transformation, such as the changes at 60 and $37^{\circ} \mathrm{C}$. Therefore, both the constants $b$ and $n$ varied with temperatures and materials, resulting an unreliable value of the activation energy.

We employed a more practical method in which the transformation rate $r$ is assumed to be the reciprocal of $t_{0.5}$

$$
r=1 / t_{0.5}
$$

where $t_{0.5}$ is the time corresponding to $50 \%$ of the saturated transformation volume.

In many cases, the isothermal transformation rate

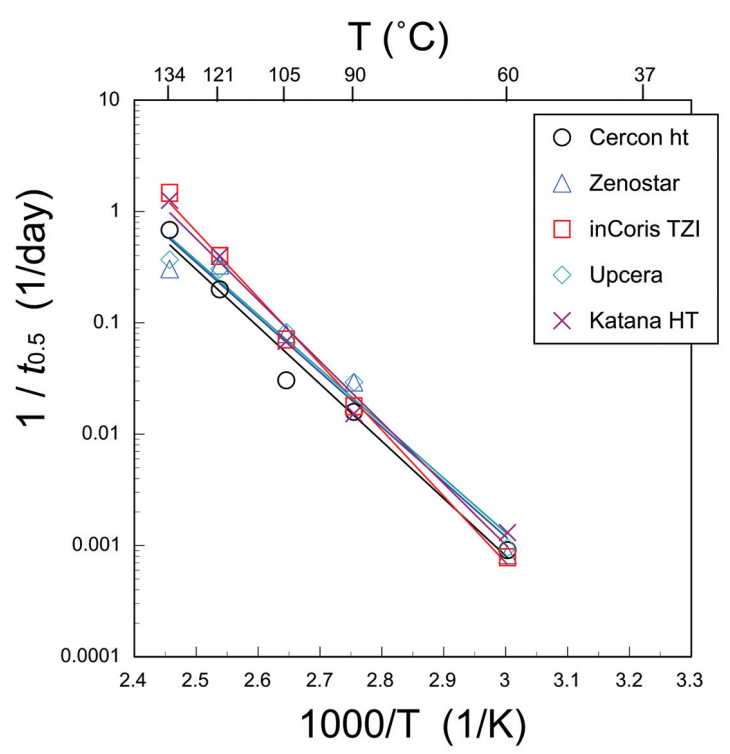

Fig. 3 Arrhenius plot between the time at 50\% - change to monoclinic phase fraction and the storage temperature of five kinds of polished dental zirconia.

is expressed by the following Arrhenius type equation:

$$
r=A \cdot \exp (-Q / R T)
$$

where $A$ is a material constant.

The process in which the transformation rate and the temperature satisfy this relationship is called a thermally activated process. Many transformation processes in solid state are thermally activated ${ }^{24-26)}$. The LTD of zirconia is also considered to depend on a thermally activated process ${ }^{18,19,23)}$. When the $t_{0.5}$ values of five kinds of polished high translucent zirconia were plotted against the reciprocal temperature, each data could be linearly regressed (Fig. 3). Using Equation (6), from the slopes, the apparent activation energies of five kinds of polished high translucent zirconia were calculated as $98.4 \mathrm{~kJ} / \mathrm{mol}$ for Cercon ht, $94.3 \mathrm{~kJ} / \mathrm{mol}$ for Zenostar, $113.9 \mathrm{~kJ} / \mathrm{mol}$ for inCoris TZI, $93.6 \mathrm{~kJ} / \mathrm{mol}$ for Upcera, and $105.2 \mathrm{~kJ} / \mathrm{mol}$ for Katana $\mathrm{HT}^{27)}$. This means that the apparent activation energies were nearly the same (average $101.1 \mathrm{~kJ} / \mathrm{mol}$ with a standard deviation of $8.5 \mathrm{~kJ} / \mathrm{mol}$ ). This value is in good agreement with the values for various zirconia in previous reports by other researchers (Table 1$)^{23,27-34)}$. This value is similar to the activation energy for oxygen vacancy diffusion extrapolated from higher temperature ${ }^{19)}$.

Although the $t_{0.5}$ value at $37^{\circ} \mathrm{C}$ was not experimentally observed for any zirconia within 5 years in this study, it can be calculated from this activation energy and Equations (5) and (6). A $t_{0.5}$ value at $37^{\circ} \mathrm{C}$ was derived as 49.1 years for Cercon ht, 29.6 years for Zenostar, 85.9 years for inCoris TZI, 26.7 years for Upcera, and 47.1 years for Katana HT. It is difficult in practice to obtain measured values at $37^{\circ} \mathrm{C}$, so it is 
Table 1 Calculated apparent activation energy for LTD of zirconia after previous papers

\begin{tabular}{|c|c|c|c|c|c|c|}
\hline Year & Author & Composition & $\begin{array}{l}\text { Temperature of } \\
\text { data collection } \\
\left({ }^{\circ} \mathrm{C}\right)\end{array}$ & Period & $\begin{array}{l}\text { Calculated } \\
\text { activation } \\
\text { energy } \\
(\mathrm{kJ} / \mathrm{mol})\end{array}$ & $\begin{array}{l}\text { Ref. } \\
\text { No }\end{array}$ \\
\hline 1985 & $\begin{array}{l}\text { Sato } \\
\text { et al. }\end{array}$ & $\mathrm{TZP}(2 \mathrm{Y}, 3 \mathrm{Y}$, and $4 \mathrm{Y})$ & $\begin{array}{l}83,95105,115 \\
\text { and } 120\end{array}$ & 7 days & $72.8-93.8$ & 28) \\
\hline 1993 & $\begin{array}{l}\text { Tsubakino } \\
\text { et al. }\end{array}$ & $\mathrm{TZP}(3 \mathrm{Y})$ & $\begin{array}{l}150,200,250, \\
\text { and } 300\end{array}$ & $\begin{array}{l}10.8 \mathrm{ks} \\
(=3 \mathrm{~h})\end{array}$ & 76.2 & 29) \\
\hline 1993 & $\begin{array}{l}\text { Shimizu } \\
\text { et al. }\end{array}$ & $\mathrm{TZP}(3 \mathrm{Y})$ & 95 & 3 years & 89.9 & 30) \\
\hline 1996 & $\begin{array}{l}\text { Fujisawa } \\
\text { et al. }\end{array}$ & $\mathrm{TZP}(3 \mathrm{Y})$ & $\begin{array}{l}37,70,95,121 \\
\text { and } 141\end{array}$ & 3 years & 97.6 & $31)$ \\
\hline 1999 & $\begin{array}{l}\text { Chevalier J } \\
\text { et al. }\end{array}$ & $\mathrm{TZP}(3 \mathrm{Y})$ & $\begin{array}{l}70,80,90,100 \\
120, \text { and } 130\end{array}$ & $\begin{array}{l}5,000 \mathrm{~h} \\
(=208 \text { days })\end{array}$ & 106 & 23) \\
\hline 2008 & $\begin{array}{l}\text { Schneider } \\
\text { et al. }\end{array}$ & $\begin{array}{l}\text { Alumina toughened zirconia } \\
{\left[80 \mathrm{wt} \% \mathrm{TZP}(3 \mathrm{Y}), 20 \mathrm{wt} \% \mathrm{Al}_{2} \mathrm{O}_{3}\right]}\end{array}$ & $\begin{array}{l}70,80,90,100, \\
111,121, \text { and } 134\end{array}$ & $\begin{array}{l}4,000 \mathrm{~h} \\
(=167 \text { days })\end{array}$ & 96.5 & $32)$ \\
\hline 2009 & $\begin{array}{l}\text { Chevalier J } \\
\text { et al. }\end{array}$ & $\begin{array}{l}\text { Zirconia toughened alumina } \\
{[17 \text { vol\% TZP ( } 3 \mathrm{Y}), 3 \text { vol\% Strontium }} \\
\left.\text { aluminate, and } 80 \text { vol } \% \mathrm{Al}_{2} \mathrm{O}_{3}\right]\end{array}$ & $\begin{array}{l}90,105,121 \\
134, \text { and } 142\end{array}$ & $\begin{array}{l}2,000 \mathrm{~h} \\
(=84 \text { days })\end{array}$ & 108 & 33) \\
\hline 2014 & $\begin{array}{l}\text { Fabbri } \\
\text { et al. }\end{array}$ & $\begin{array}{l}\text { Zirconia toughened alumina } \\
{\left[40 \mathrm{wt} \% \mathrm{TZP}(3 \mathrm{Y}), 60 \mathrm{wt} \% \mathrm{Al}_{2} \mathrm{O}_{3}\right]}\end{array}$ & 90,121, and 134 & $\begin{array}{l}3,000 \mathrm{~h} \\
(=125 \text { days })\end{array}$ & 99 & 34) \\
\hline 2015 & Ban e al. & TZP (3Y), and PSZ (4Y) & $\begin{array}{l}37,60,90,105 \\
121, \text { and } 134\end{array}$ & 5 years & $\begin{array}{l}93.6-113.9 \\
(101.1 \pm 8.5)\end{array}$ & 27) \\
\hline
\end{tabular}

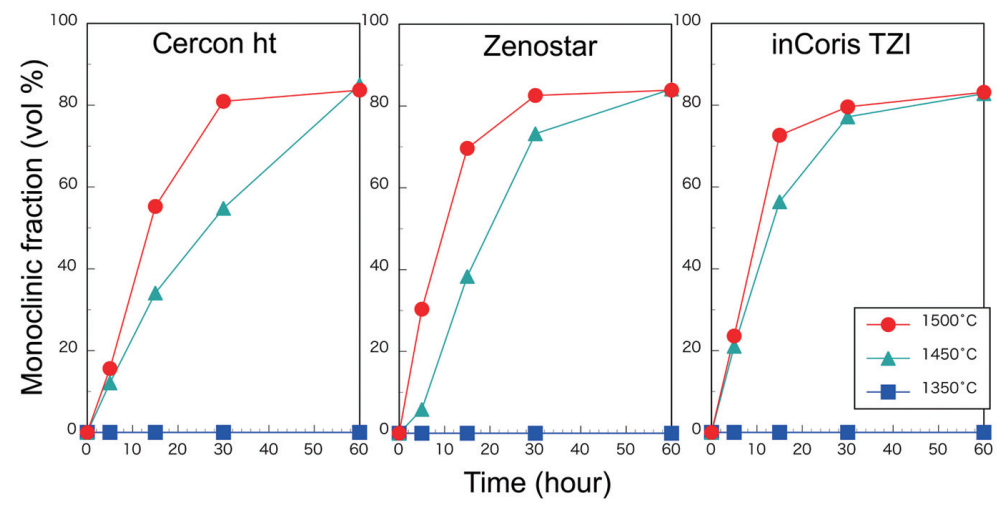

Fig. 4 Monoclinic fraction of high translucent zirconia (3Y) (Cercon ht, Zenostar, and inCoris TZI) as fired at $1,350,1,450$, and $1,500^{\circ} \mathrm{C}$ after autoclaving at $134^{\circ} \mathrm{C}$.

necessary to estimate theoretically, as above.

It can be determined that zirconia restoration can endure use in the oral cavity for several decades. Therefore, it is not appropriate to point out the LTD of zirconia as a drawback of dental zirconia. The LTD test of zirconia in autoclave at 121 or $134^{\circ} \mathrm{C}$ should be considered just an accelerated test of the degradation phenomenon in the vicinity of the oral cavity temperature.

\section{Effect of firing temperature}

LTD is primarily dependent on the ceramic microstructure, such as grain size, yttrium content, and density ${ }^{35)}$. Therefore, the firing temperature is one of the most effective factors on LTD. We evaluated the effect of a firing temperature on LTD at $134^{\circ} \mathrm{C}$ of three kinds of high translucent zirconia (3Y). The specimen fired at $1,500^{\circ} \mathrm{C}$ showed a higher degradation rate than that at $1,450^{\circ} \mathrm{C}$ (Fig. 4). The specimen fired at $1,350^{\circ} \mathrm{C}$ did not show any degradation ${ }^{36)}$. A higher firing temperature results in the formation of a larger grain in the cubic phase having enrich yttrium, which in turn leads to a depletion of yttrium in the neighboring tetragonal 

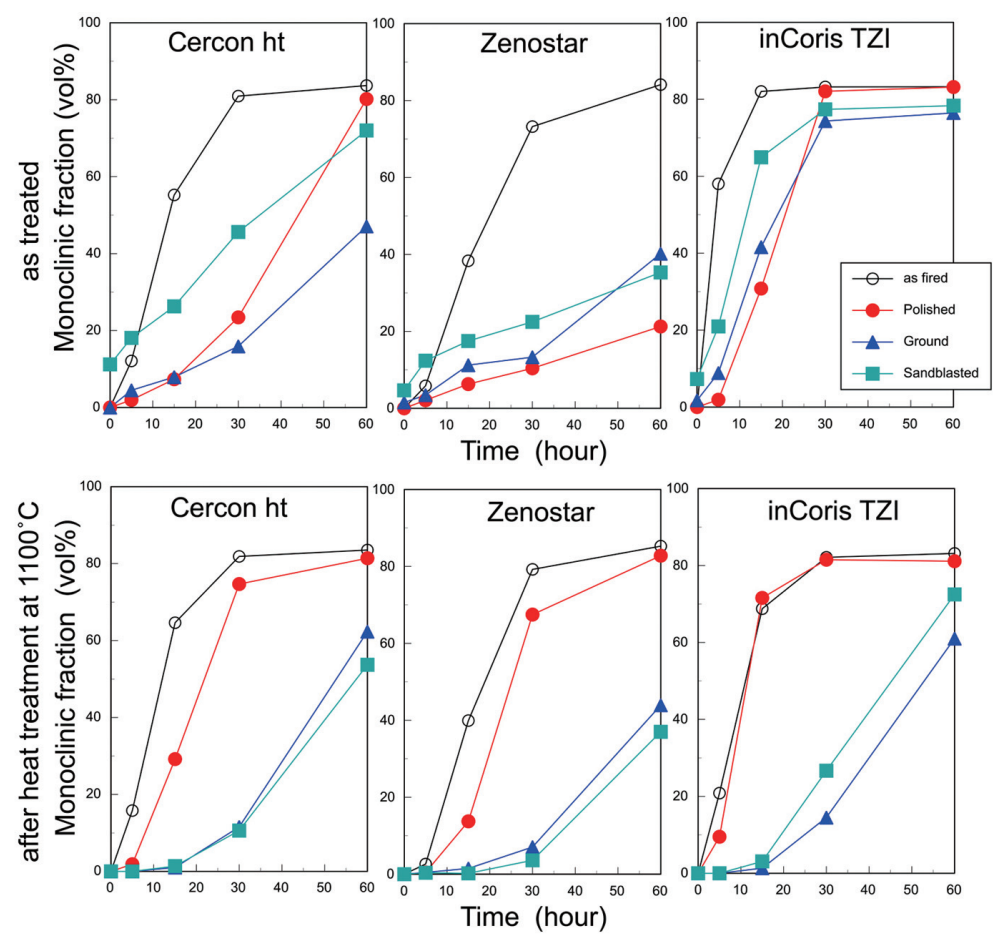

Fig. 5 Monoclinic fraction of high translucent zirconia (3Y) (Cercon ht, Zenostar, and inCoris TZI) as fired, polished, ground, and sandblasted after autoclaving at $134^{\circ} \mathrm{C}$ before (upper) and after (lower) heat treatment $\left(1,100^{\circ} \mathrm{C}, 30 \mathrm{~min}\right)$.

grains $^{37)}$. These grains will act as nucleation sites for tetragonal-to-monoclinic transformation ${ }^{29)}$. Then, a higher firing temperature results in higher susceptibility in LTD. However, a lower firing temperature results in lower light translucency. In the case of high translucent zirconia, judging from the balance between LTD and translucency, firing at $1,450^{\circ} \mathrm{C}$ for $2 \mathrm{~h}$ is the most common $^{10)}$.

\section{Effect of surface finish and heat treatment}

It has been demonstrated that the surface treatment of zirconia has significant effects on its mechanical and chemical properties ${ }^{37-41)}$. We investigated the changes in the monoclinic content of three kinds of high translucent zirconia (3Y) as fired, polished, ground, and sandblasted (alumina particle size $70 \mu \mathrm{m}$ ) after autoclaving at $134^{\circ} \mathrm{C}$ (Fig. 5 upper). The monoclinic fraction of the specimens as fired were almost completely saturated to about $80 \%$ at $30 \mathrm{~h}$ of autoclaving. The monoclinic fraction of the specimens as polished and ground was significantly smaller than that as fired in the initial stage of the autoclaving. In case of sandblasting, the monoclinic content before autoclaving was already $11.2 \%$ for Cercon ht, $4.7 \%$ for Zenostar, and $7.3 \%$ for inCoris TZI, which depends on stress induced transformation due to the sandblasting ${ }^{5)}$. However, the sandblasted specimen showed the smaller monoclinic fraction than the as fired one after autoclaving. It was confirmed that surface treatments such as polishing, grinding, and sandblasting suppressed the degradation in the initial stage of the autoclaving.

FE-SEM observation demonstrated that fine zirconia crystal grains of 300 to $400 \mathrm{~nm}$ are exposed on the surface of the specimen as fired. Whereas the polished surface is covered with a smooth amorphous-like layer, the ground surface has many scratches due to the sliding of the particles of the diamond point, and the sandblasted surface has a randomly roughened uneven state (Fig. 6 upper). From XRD patterns (Fig. 7 lower), the polished surface seems to be covered with an amorphous-like layer, the ground surface forms a small amount of a rhombohedral phase due to the stress-induced cubicrhombohedral transformation ${ }^{42,43)}$, and the sandblasted surface forms a monoclinic phase due to the stressinduced tetragonal-monoclinic transformation ${ }^{5,40)}$.

After the heat treatment, the monoclinic fractions of the specimens as fired showed no changes, whereas those as polished dramatically increased and those as ground and sandblasted decreased (Fig. 5). FE-SEM observation revealed that the microstructure of the surface as fired showed no changes, whereas quite fine grain structures of the specimens, except those as fired, were observed after the heat treatment (Fig. 6 lower). XRD patterns of the specimen as fired showed no changes after the heat treatment (Fig. 7). However, the diffraction peak assigned to the tetragonal (101) around $30^{\circ}$ in $2 \theta$ of the polished specimens increased and the intensity ratio of the tetragonal (002) to (200) around $35^{\circ}$ in $2 \theta$ changed. 

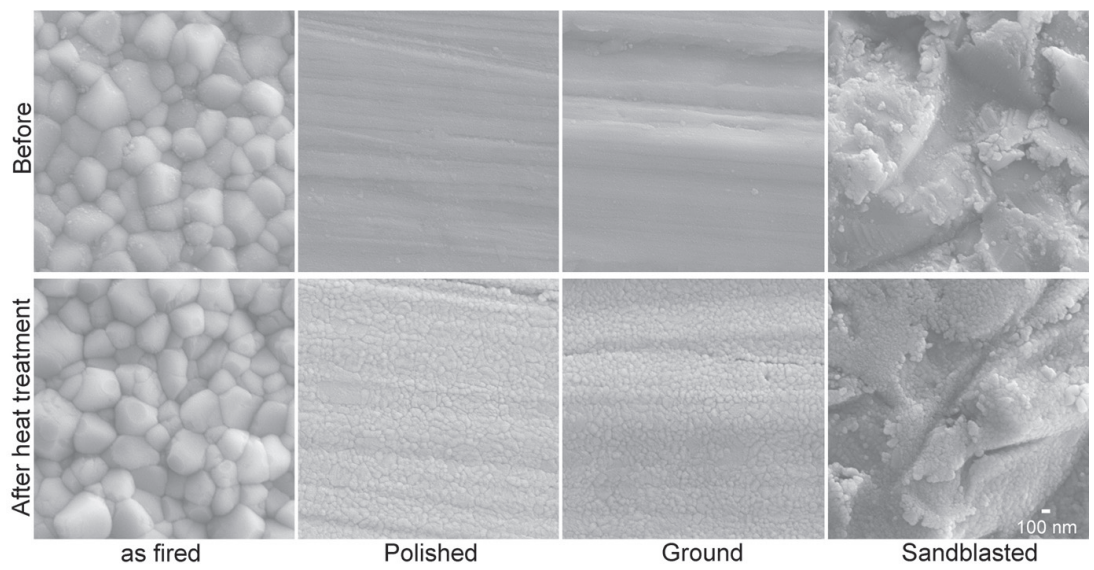

Fig. 6 Secondary electron images of Cercon ht (3Y) as fired, polished, ground, and sandblasted before (upper) and after (lower) heat treatment $\left(1,100^{\circ} \mathrm{C}, 30 \mathrm{~min}\right)$.

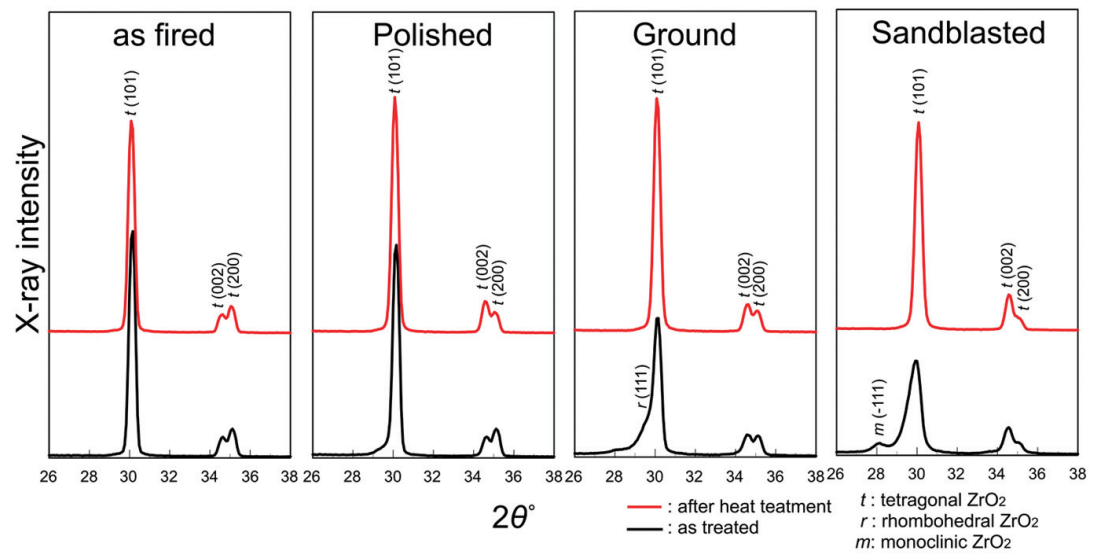

Fig. 7 X-ray diffraction pattern of Cercon ht (3Y) as fired, polished, ground, and sandblasted before (lower) and after (upper) heat treatment $\left(1,100^{\circ} \mathrm{C}, 30 \mathrm{~min}\right)$.

The diffraction peak of the rhombohedral (111) around $29^{\circ}$ in $2 \theta$ of the ground specimen disappeared and the tetragonal (101) increased after the heat treatment. Furthermore, the diffraction peak of the monoclinic (-111) around $28^{\circ}$ in $2 \theta$ of the sandblasted specimen disappeared and the tetragonal (101) and (002) increased after the heat treatment. This means that the surfaces of the tetragonal phase orients to the $c$-axis after surface treatment and subsequent heat treatment. This phenomenon is known as ferroelastic domain switching 44-46). Virkar and Matsumoto demonstrated that, in tetragonal zirconia, the $a$-axis and the $c$-axis of the tetragonal lattice having a domain structure are interchanged and reoriented without undergoing phase transition from the tetragonal to monoclinic under stress ${ }^{44)}$. This can be used to explain that zirconia sometimes shows high toughness, even though the phase transition from the tetragonal to monoclinic does not occur.

It is also assumed that the tetragonal lattice is distorted by stress, such as with polishing, grinding, and sandblasting. And the outermost layer of the polished specimen seems to be in a nearly amorphous state. This is similar to the formation of an amorphous layer called the Beilby layer at the outermost layer of polished metal. The amorphous layer seems to act as a barrier against chemicals attaching to the tetragonal phase. When the amorphous layer on the surface of the zirconia is subjected to heat treatment, relief of the fine microstructure due to recrystallization appears (Fig. 6). As the original residual stress increases, the degree of refinement tends to increase. This phenomenon is also similar to that which occurs in metal. After the disappearance of the amorphous state by heat treatment, LTD increases to a level similar to that of the specimen as fired (Fig. 5). In addition, rhombohedral and monoclinic crystals generated by stress load disappear by heat treatment; only tetragonal crystals are formed, and residual stress disappears. From these characterization results, by polishing, grinding and sandblasting the surface of 
the zirconia, a thin amorphous layer is formed in the outermost layer. In addition, tetragonal grains oriented to the $c$-axis and then refined are generated between the outermost layer and the plastic deformation layer. It has been reported that the main mechanism of wear on zirconia is plastic deformation ${ }^{46-50)}$. Kondo et al. suggested that, considering that zirconia has high toughness and low thermal conductivity, the grinding point temperature becomes high, so it is comprehensible that the plastic deformation induced by grinding causes chip generation, as with metals ${ }^{48)}$. It is also possible that the residual stress acting as compressive stress on the surface contributes to the acceleration of LTD, as with the stress-corrosion of metals. Therefore, when the surface stresses for the ground and sandblasted zirconia disappear by heat treatment, the LTD decreases with them.

It can be assumed that LTD behavior at $37^{\circ} \mathrm{C}$ is similar to that at $134^{\circ} \mathrm{C}$, judging from the law of Mehl-Avrami-Johnson mentioned above. This is very important in the case of monolithic zirconia crowns, not only for reducing the wear of the antagonist teeth, but also to suppress LTD. Therefore, it is recommended that the final surface of the dental restoration of zirconia be mirror polished.

\section{Effect of yttria content}

As mentioned above, a higher yttria content results in the formation of more stable tetragonal and cubic zirconia. We investigated LTD at $134^{\circ} \mathrm{C}$ of surface treated 4Y zirconia (MY Zirconia NHT, Yamahachi, Aichi, Japan), 5Y zirconia (ceramill zolid fx, Amann Girrbach, Koblach, Austria), and 6Y zirconia (Nacera Pearl Q ${ }^{3}$, Duceram Medical Ceramics, Dortmund, Germany) ${ }^{51)}$. Compared with the LTD behavior of $3 \mathrm{Y}$ (Fig. 5 upper), the monoclinic fraction of $4 \mathrm{Y}, 5 \mathrm{Y}$, and $6 \mathrm{Y}$ zirconia after autoclaving are significantly smaller (Fig. 8). This may depend on the subsequent two reasons. First, the tetragonal fractions in $4 \mathrm{Y}-6 \mathrm{Y}$ zirconia are lower than $3 \mathrm{Y}$ and result in a reduction of raw material for the transformation. Second, the amount of yttria in tetragonal grains is sufficient to resist the LTD, even after the segregation of yttria following the final firing illustrated in Fig. 5. Thus, the LTD of 3Y increases with the firing temperature, whereas the LTD of $5 \mathrm{Y}$ and $6 \mathrm{Y}$ does not change.

Although the monoclinic fractions of the sandblasted surface of $4 \mathrm{Y}$ and $6 \mathrm{Y}$ are slightly high, the LTD of the three polished zirconia are negligible. It can be concluded that the influence of yttria content on the LTD of zirconia is quite large and the degradation is mostly suppressed when it exceeds 4 moles.

\section{Effect of alumina content}

Alumina content affects LTD; $40 \mathrm{wt} \%$ alumina almost perfectly restrained the transformation ${ }^{35)}$. It has also been reported that alumina grains play a major role in resisting the volume expansion of the zirconia grains accompanying LTD $^{52)}$. With even a small addition of alumina $\left(0.25 \mathrm{wt} \%^{29)}\right.$ and $\left.1.2 \mathrm{wt} \%{ }^{53)}\right)$, LTD was inhibited. Although the alumina content of inCoris ZI (3Y-HA) (Dentsply Sirona) was only $0.286 \mathrm{wt} \%$, alumina grains existed among zirconia grains ${ }^{54,55)}$. However, the alumina content of inCoris TZI (3Y) (Dentsply Sirona) was less than 0.05 wt\% and no alumina grains were observed among the zirconia grains ${ }^{54,55)}$. It can be concluded that these small amounts of alumina grains are effective in the inhibition of LTD. This can be interpreted by the increase in grain size and the heterogeneous distribution of $\mathrm{Y}^{3+}$ ions within tetragonal grains ${ }^{56,57)}$.

On the contrary, translucency decreases with the alumina grains, as mentioned above. Thus, the translucency of zirconia strongly relates to LTD. These results indicate that the high translucent zirconia (3Y) has a better translucency than the conventional zirconia (3Y-HA), but is more susceptible to LTD.

\section{CHEMICAL REACTION AT HIGH TEMPERATURE}

Zirconia is quite chemically stable against various

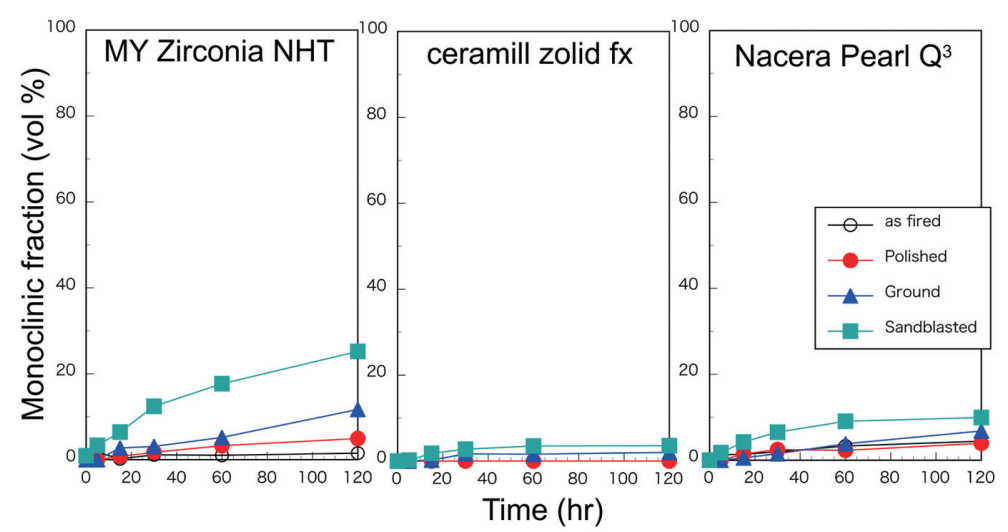

Fig. 8 Monoclinic fraction of high translucent zirconia (MY Zirconia NHT [4Y], ceramill zolid fx [5Y], and Nacera Pearl $\mathrm{Q}^{3}[6 \mathrm{Y}]$ ) as fired, polished, ground, and sandblasted after autoclaving at $134^{\circ} \mathrm{C}$. 
materials around temperatures that exist in the oral cavity. However, it reacts with some materials at temperatures above $700^{\circ} \mathrm{C}$. Furthermore, the stress induced transformation from the tetragonal to monoclinic phase rarely occurs at temperatures above $700^{\circ} \mathrm{C}^{46)}$, which results in a reduction of strength ${ }^{58)}$. The high reactivity at high temperatures may be caused by the movement of oxygen vacancies ${ }^{47)}$. In fact, the heating of zirconia under vacuum or in reduced atmosphere decreases the oxygen content and blackens the surface. When a Nd-YAG laser irradiated the zirconia (3Y and Nanozr) surface under atmospheric pressure, the zirconia surface blackened because of the photothermal mechanism and formed cracks due to melting and solidification, which resulting in a reduction of mechanical strength ${ }^{9}$.

Furthermore, some dental materials strongly affect the surface characteristics of dental zirconia after the final firing at $1,350-1,450^{\circ} \mathrm{C}^{59)}$. When presintered zirconia discs (3Y and Nanozr) were contaminated with orthophosphoric acid, phosphate-based investment material powder, and phosphoric acid etching gel, large grains of 1 to $2 \mu \mathrm{m}$ were formed and cracks were clearly observed after the final firing. Judging from the $\mathrm{X}$-ray diffraction pattern, these large grains seemed to be monoclinic zirconia ${ }^{60}$. On the surface of the zirconia contaminated with gypsum powder, much larger grains of around $10 \mu \mathrm{m}$ were formed. The X-ray diffraction pattern demonstrated that these large particles were assigned as $\mathrm{CaZrO}_{3}{ }^{60}$. We applied the reaction between a calcium compound and zirconia at high temperature on the improvement of bioactivity of the zirconia surface ${ }^{61,62)}$.
Therefore, it is concluded that zirconia reacts well with some materials at high temperatures owing to the movement of oxygen vacancies in the zirconia lattice.

\section{EROSION IN WATER-BASED SOLUTIONS}

The chemical durability of zirconia is excellent at temperatures in the oral cavity, and erosion in acid and alkali solution is rare. We confirmed that the surface of zirconia (3Y-HA and Nanozr) had high resistivity against inorganic acid such as nitric acid, hydrochloric acid, sulfuric acid, and phosphoric acid at $60^{\circ} \mathrm{C}^{63)}$. However, regarding fluoric acid, after soaking in 6, 12, and $24 \%$ fluoric acid solutions at room temperature, zirconia surfaces were eroded at higher acid concentrations. The high translucent zirconia ( $3 \mathrm{Y}$ and $5 \mathrm{Y}$ ) showed similar behavior.

In milder environments such as $4 \%$ lactic acid ( $\mathrm{pH}$ 1.9) and $0.1 \mathrm{~N} \mathrm{KOH} \mathrm{(pH12.6)} \mathrm{solution,} \mathrm{the} \mathrm{surface} \mathrm{of}$ zirconia (3Y and $5 \mathrm{Y}$ ) showed no remarkable changes even after 30 days at $60^{\circ} \mathrm{C}$, whereas glass ceramics and hybrid resins showed severe damage ${ }^{64,65)}$. In glass ceramics, the difference in chemical properties of the matrix glass and the dispersed crystal clearly appears, and distinct surfaces are displayed depending on each microstructure. IPS e.max CAD shows selective dissolution of the matrix glass, resulting in a clear edge of a needle-shaped lithium disilicate. Hybrid resins such as Cerasmart also show selective dissolution of the filler (Fig. 9).

In saline solution at $90^{\circ} \mathrm{C}$, the glass ceramics and the hybrid resin showed slightly similar dissolutions,
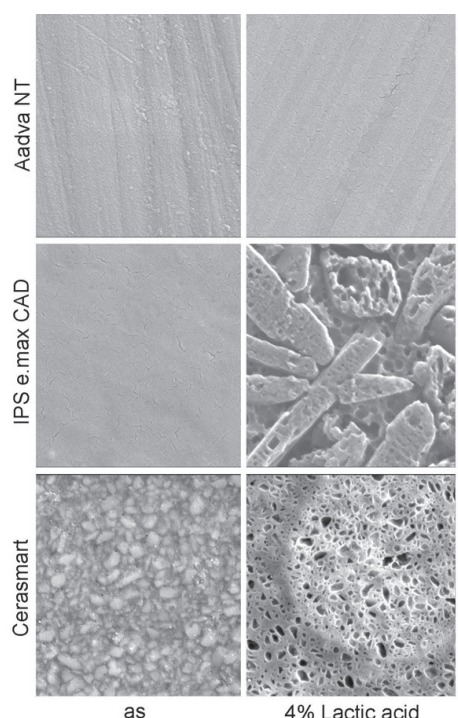

for 30 days at $60^{\circ} \mathrm{C}$
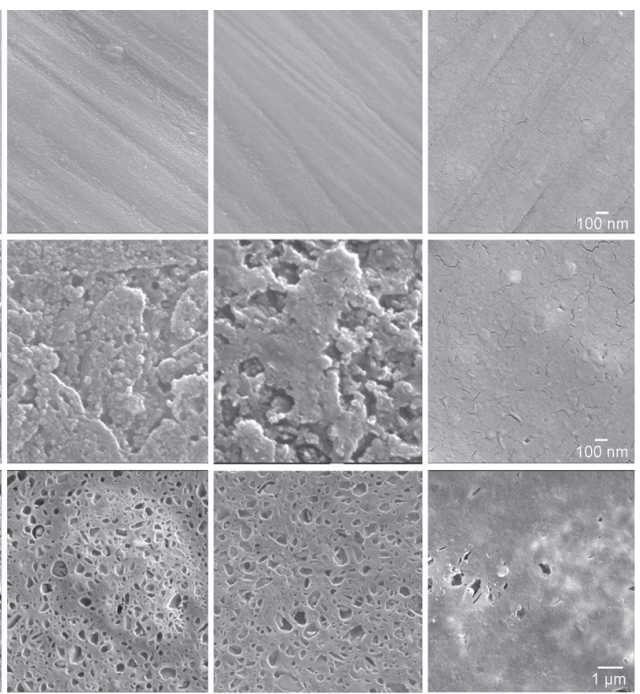

Saline

for 30 days at $90^{\circ} \mathrm{C}$

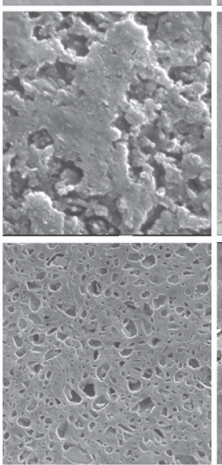

$0.1 \mathrm{~N} \mathrm{KOH}$ for 30 days at $60^{\circ} \mathrm{C}$ for 40 hours at $134^{\circ} \mathrm{C}$

Fig. 9 Secondary electron images of high translucent zirconia (5Y) (Aadva NT), lithium disilicate (IPS e.max CAD), and hybrid resin (Cerasmart) before and after soaking in $4 \%$ lactic acid for 30 days at $60^{\circ} \mathrm{C}$, saline solution for 30 days at $90^{\circ} \mathrm{C}$, and $0.1 \mathrm{~N} \mathrm{KOH}$ for 30 days at $60^{\circ} \mathrm{C}$, and after autoclaving for $40 \mathrm{~h}$ at $134^{\circ} \mathrm{C}$. 


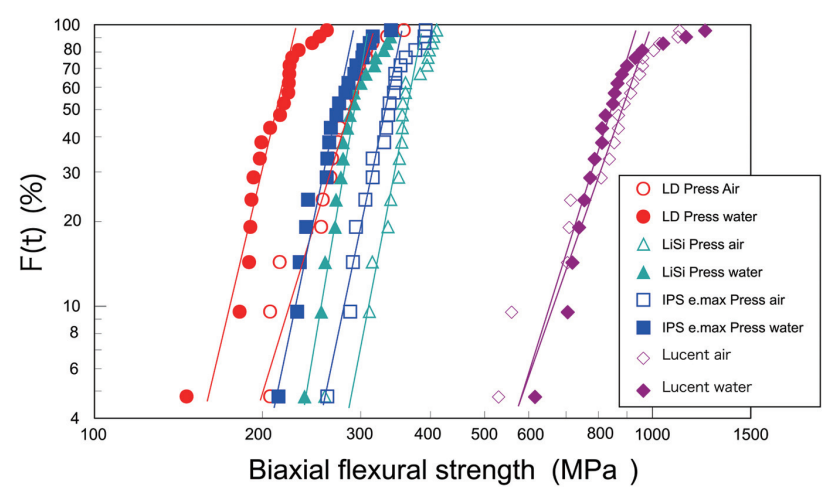

Fig. 10 Weibull plots of the biaxial flexural strengths of three glass ceramics (LD Press, LiSi Press, and IPS e.max Press) and high translucent zirconia (5Y) (ZR-SS Lucent White) tested in air and water.

but the zirconia showed no changes. When autoclaved at $134^{\circ} \mathrm{C}$, glass ceramics and the hybrid resin showed little dissolution, and the zirconia showed no changes.

The presence of glass strongly affects the properties of the glass ceramics. For example, the strength of glass decreases after contact with water, especially under a loaded condition ${ }^{66,67)}$. Our previous studies revealed that biaxial flexure strengths of dental porcelains fused to metal in water were $20 \%$ lower than those in air ${ }^{68-70)}$. Dental porcelains fused to metal contain approximately 70 vol\% of feldspathic glass, while pressureable lithium disilicates contain $30 \mathrm{vol} \%$ of zirconia reinforced glass. Thus, there is concern whether the strength of pressureable lithium disilicates decreases in contact with water such as in the oral cavity. We determined the biaxial flexural strengths of three kinds of pressureable lithium disilicates in air and water at room temperature, in comparison with a high translucent zirconia $(5 \mathrm{Y})^{71)}$. The biaxial flexural strengths of three glass ceramics in water were about $20 \%$ lower than the value of those in the air. Weibull analysis showed that the values in water were clearly lower than those in air (Fig. 10). However, the biaxial bending strength of the zirconia in water was not as statistically significant as the values in the air. In addition, in the Weibull analysis, no clear difference was found between the distribution of both. Therefore, it is concluded that zirconia has high water resistance and hydrolysis in water hardly occurs at temperatures in oral cavity, indicating that the strength does not decrease in water.

Although the chemical reactivity of zirconia increases with increasing temperature as mentioned above, it can be reconfirmed that zirconia has the best chemical durability under the same test conditions when compared with other dental restorative materials.

\section{DISCOLORATION}

Restorative materials are required for excellent chemical
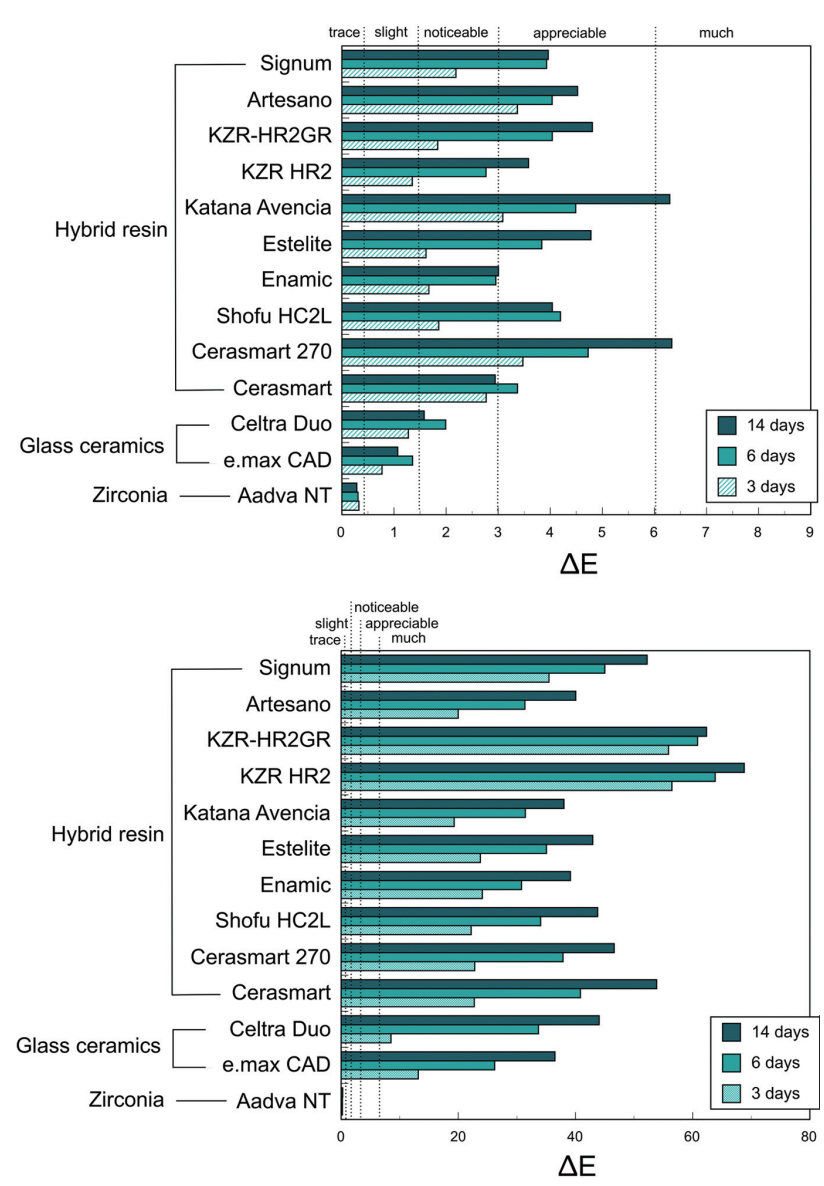

Fig. 11 Color difference $(\Delta E)$ of $\mathrm{CAD} / \mathrm{CAM}$ materials before and after soaking in a red wine (upper) and $0.1 \%$ rhodamine $\mathrm{B}$ solution (bottom) for 3,6 , and 14 days at $37^{\circ} \mathrm{C}$.

durability against saliva, food, and drink. Metals dissolve to become metal ions through corrosion, and sometimes discoloration occurs on the surface due to the formation of colored compounds. Resin materials inevitably absorb water, and easily discolor depending on the degree of polymerization of the resin matrix. Because the degree of polymerization of photopolymerized composite resin is low due to the complex structure of dimethacrylate monomer, photopolymerized composite resin shows some discoloration in water-based solution ${ }^{72}$. Because the hybrid resin for CAD/CAM has a high degree of polymerization because of heat polymerization, it shows little discoloration in saline solution even at $90^{\circ} \mathrm{C}^{73)}$. However, in acidic red solutions such as rhodamine solution or red wine, a marked discoloration occurs in hybrid resins for CAD/CAM (Fig. 11). Hybrid resins show noticeable or appreciable discoloration in red wine and glass ceramics show slight discoloration after 3 days soaking in red wine at $37^{\circ} \mathrm{C}$. Both showed much discoloration after 3 days soaking in rhodamine $\mathrm{B}$ solution at $37^{\circ} \mathrm{C}$. However, zirconia showed only trace discoloration in both solutions. It seems that noticeable 
and appreciable discolorations of glass ceramics and hybrid resins depends on the erosion of the glass filler and glass matrix. Therefore, it can be reconfirmed that zirconia shows no discoloration in any solutions because zirconia has no glass.

\section{CONCLUSIONS}

The performance evaluation for zirconia when it is used industrially is made under a high temperature environment. The phase transformation rate is largest at $200-300^{\circ} \mathrm{C}$, which is referred to as low because it is low temperature when testing industrial parts made of zirconia. However, it is an impossibly high temperature condition for the dental restorative material. Therefore, it is not appropriate to point out the LTD of zirconia as a drawback of dental zirconia. The LTD test of zirconia after autoclaving at 121 or $134^{\circ} \mathrm{C}$ should be considered as an accelerated test of the degradation phenomenon at temperatures in the oral cavity. From the evaluation results of several chemical durability tests of many dental restorative materials under various environments, zirconia was judged to exhibit superior chemical durability among various dental restorative materials tested.

\section{ACKNOWLEDGMENTS}

The author is indebted to the staffs of the Department of Dental Materials Science, School of Dentistry, Aichi Gakuin University and the graduate students I taught at Graduate School of Medical and Dental Sciences, Kagoshima University.

\section{REFERENCES}

1) Filser F, Kocher P, Gauckler LJ. Net-shaping of ceramic components by direct ceramic machining. Assembly Autom 2003; 23: 382-390.

2) Ban S. Reliability and properties of core materials for allceramic dental restorations. Jpn Dent Sci Rev 2008; 44: 3-21.

3) Piconi C, Maccauro G. Zirconia as a ceramic biomaterial. Biomaterials 1999; 20: 1-25.

4) Ban S, Sato H, Suehiro Y, Nakanishi H, Nawa M. Biaxial flexure strength and low temperature degradation of Ce-TZP/ $\mathrm{Al}_{2} \mathrm{O}_{3}$ nanocomposite and Y-TZP as dental restoratives. $\mathrm{J}$ Biomed Mater Res B Appl Biomater 2008; 87B: 492-498.

5) Sato H, Yamada K, Pezzotti G, Nawa M, Ban S. Mechanical properties of dental zirconia ceramics changed with sandblasting and heat treatment. Dent Mater J 2008; 27: 408-414.

6) Ban S, Suehiro Y, Nakanishi H, Nawa M. Fracture toughness of dental zirconia before and after autoclaving. J Ceram Soc Jpn 2010; 118: 406-409.

7) Yamashita D, Machigashira M, Miyamoto M, Takeuchi $\mathrm{H}$, Noguchi K, Izumi Y, et al. Effect of surface roughness on initial responses of osteoblast-like cells on two types of zirconia. Dent Mater J 2009; 28: 461-470.

8) Okuda Y, Noda M, Kono H, Miyamoto M, Sato H, Ban S. Radio-opacity of core materials for all-ceramic restorations. Dent Mater J 2010; 29: 35-40.

9) Noda M, Okuda Y, Tsuruki J, Minesaki Y, Takenouchi Y, Ban S. Surface damages of zirconia by Nd:YAG dental laser irradiation. Dent Mater J 2010; 29: 536-541.

10) Ban S. Perfect guide book for CAD/CAM materials, 1-96, Ishiyaku, Tokyo, 2017.

11) The Dental Adviser, "3M ESPE Lava crowns and bridges (7 years)," Vol.27, No.7, 2010. Available: http://www. dentaladvisor.com/clinical-evaluations/evaluations/3m-espelava-crownsand-bridges-7-yr.shtml

12) Bona $\mathrm{AD}$, Kelly J. The clinical success of all-ceramic restorations. J Am Dent Assoc 2008; 139 (Suppl 4): 8S-13S.

13) Ariel J, Raigrodski AJ, Hillstead MB, Meng GK, Chung KH. Survival and complications of zirconia-based fixed dental prostheses: A systematic review. J Prosthet Dent 2012; 107: 170-177.

14) Ban S. Novel development of dental zirconia. J J Dent Mater 2016; 35: 257-260.

15) Yoshimura M, Noma T, Kawabata K, Somiya S. Role of $\mathrm{H}_{2} \mathrm{O}$ on the degradation process of Y-TZP. J Mater Sci Lett 1987; 6: 465-467.

16) Masonis J, Bourne R, Ries M, McCalden R, Salehi A, Kelman D. Zirconia femoral head fractures: A clinical and retrieval analysis. J Arthroplasty 2004; 19: 898-905.

17) Maccauro G, Piconi C, Burger W, Pilloni L, De Santis E, Muratori F, et al. Fracture of a Y-TZP ceramic femoral head. J Bone Joint Surg 2004; 86B: 1192-1196.

18) Chevalier J, Drouin JM, Cales B. Low temperature ageing behaviour of zirconia hip joint heads. Bioceramics 1997; 10: 135-137.

19) Chevalier J, Gremillard L, Virkar AV, Clarke DR. The tetragonal-monoclinic transformation in zirconia: Lessons learned and future trends, J Am Ceram Soc 2009; 92: 19011920.

20) Ban S. Technical factors affecting the properties of dental zirconia. Proc Intern Dent Mater Congress 2011: 70-79.

21) Toraya H, Yoshimura M, Somiya S. Calibration curve for quantitative analysis of the monoclinic-tetragonal $\mathrm{ZrO}_{2}$ system by X-ray diffraction. J Am Ceram Soc 1984; 67: C119C121.

22) Garvie RC, Nicholson PS. Phase analysis in zirconia systems. J Am Ceram Soc 1972; 55: 303-305.

23) Chevalier J. Low-temperature aging of Y-TZP ceramics. J Am Ceram Soc 1999; 82: 2150-2154.

24) Thornton JA. High rate thick film growth. Ann Rev Mater Sci 1977; 7: 239-260.

25) Medina SF, Farbregue P. Activation energy in the static recrystallization of austenite. J Mater Sci 1991; 26: 54275432.

26) Liu F, Sommer F, Bos C, Mittemeijer EJ. Analysis of solid state phase transformation kinetics: models and recipes. Int Mater Rev 2007; 52: 193-212.

27) Ban S, Suzuki T, Ando M, Kawai T. Kinetic analysis of low temperature degradation of dental zirconia. J J Dent Mater 2015; 34: 69. (Abst. A-12)

28) Sato T, Shimada M. Transformation of yttria-doped tetragonal $\mathrm{ZrO}_{2}$ polycrystals by annealing in water. $\mathrm{J} \mathrm{Am}$ Ceram Soc 1985; 68: 356-358.

29) Tsubakino H, Sonoda K, Nozato R. Martensite transformation behaviour during isothermal ageing in partially stabilized zirconia with and without alumina addition. J Mater Sci Lett 1993; 12: 196-198.

30) Shimizu K, Oka M, Kumar P, Kotoura Y, Yamamuro $\mathrm{T}$, Makinouchi K, et al. Time-dependent changes in the mechanical properties of zirconia ceramic. J Biomed Mater Res 1993; 27: 729-734.

31) Fujisawa A, Shimotoso T, Masuda S, Makinouchi K. The development of zirconia ball for T.H.R. with a high mechanical strength, low phase transformation. Bioceramics 1996; 9: 495-498.

32) Schneider J, Begand S, Kriegel R, Kaps C, Glien W, Oberbach T. Low-temperature aging behavior of alumina-toughened 
zirconia. J Am Ceram Soc 2008: 91: 3613-3618.

33) Chevalier J, Grandjean S, Kuntz M, Pezzotti G. On the kinetics and impact of tetragonal to monoclinic transformation in an alumina/zirconia composite for arthroplasty applications. Biomaterials 2009; 30: 5279-5282.

34) Fabbri P, Piconi C, Burresi E, Magnani G, Mazznti F, Mingazzini C. Lifetime estimation of a zirconia-alumina composite for biomedical applications. Dent Mater 2014; 30: 138-142.

35) Lawson S. Environmental degradation of zirconia ceramics. J Euro Ceram Soc 1995; 15: 485-502.

36) Ban S, Suzuki T, Kawai T, Kono H. Relation between low temperature degradation and surface treatment of high translucent zirconia. J J Dent Mater 2013; 32: 94. (Abst A-13)

37) Matsui K. Phase-transformation mechanism in yttriastabilized tetragonal zirconia polycrystal: discovery of grain boundary segregation-induced phase transformation. TOSOH Research \& Technology Review 2010; 10: 3-15.

38) Kosmac T, Oblak C, Jevnikar P, Funduk N, Marion L. The effect of surface grinding and sandblasting on flexural strength and reliability of Y-TZP zirconia ceramic. Dent Mater 1999; 15: 426-433.

39) Curtis AR, Wright AJ, Fleming GJP. The influence of surface modification techniques on the performance of a Y-TZP dental ceramic. J Dent 2006; 34: 195-206.

40) Deville A, Chevalier J, Gremillard L. Influence of surface finish and residual stresses on the ageing sensitivity of biomedical graded zirconia. Biomaterials 2006; 27: 21862192.

41) Ban S, Sakakibara T, Yoshihara K, Takeuchi M, Kawai T, Murakami H, et al. Surface properties of dental zirconia after clinical grinding and polishing. Key Eng Mater 2013; 529530: 501-506.

42) Hasegawa H. Rhombohedral phase produced in abraded surfaces of partially stabilized zirconia. J Mater Sci Lett 1983; 2: 91-93.

43) Denry IL, Holloway JA. Microstructural and crystallographic surface changes after grinding zirconia-based dental ceramics. J Biomed Mater Res B Appl Biomater 2006; 76B: 440-448.

44) Virkar AV, Matsumoto RLK. Ferroelastic domain switching as a toughening mechanism in tetragonal zirconia. $\mathrm{J} \mathrm{Am}$ Ceram Soc 1986; 69: C224-C226.

45) Li BS, Cherng JS, Bowman KJ, Chen IW. Domain switching as a toughening mechanism in tetragonal zirconia. J Am Ceram Soc 1988; 71: C362-C364.

46) Kiguchi T, Urushihara W, Saiki A, Shinozaki K, Mizutani N. Effect of stress and temperature on ferroelastic domain switching of partially stabilized zirconia pseudo-single crystals. J Ceram Soc Jpn 1996; 104: 529-534.

47) Kiguchi T, Saiki A, Shinozaki K, Mizutani N. Relation between oxygen vacancy and ferroelastic domain switching in tetragonal zirconia pseudo-single crystals. J Ceram Soc Jpn 1996; 104: 1106-1111.

48) Kondo Y, Tsukuda A, Kuroshima Y, Okada S. Consideration to chip generation in grinding of ceramic materials. J Ceram Soc Jpn 1989; 97: 513-519.

49) Fischer TE, Anderson MP, Jahanmir S. Influence of fracture toughness on the wear resistance of yttria-doped zirconium oxide. J Am Ceram Soc 1989; 72: 252-257.

50) He Y, Winnubst L, Burggraaf AJ, Verweij H, van der Varst PGT, de With B. Grain-size dependence of sliding wear in tetragonal zirconia polycrystals. J Am Ceram Soc 1996; 79: 3090-3096.

51) Ban S, Iwata J, Asakura M, Kawai T. Effect of yttria content on low temperature degradation of dental zirconia. J J Dent Mater 2019; 38 (Special Issue 73): 7. (Abst A-6)

52) Sato T, Shimada M. Crystalline phase change in yttriapartially-stabilized zirconia by low-temperature annealing. J
Am Ceram Soc 1984; 67: C212-C213.

53) Kosmac T, Dakskobler A, Oblak C, Jevnikar P. The strength and hydrothermal stability of y-TZP ceramics for dental applications. Intern J Appl Ceram Tec 2007; 4: 164-174.

54) Ban S, Suzuki T, Sakakibara T, Yoshihara K, Kawai T. Optical properties of dental zirconia. Proc.12th Asian Bioceram Sympo 2012.11.18-21, Tainan, Taiwan. (Abst P-19)

55) Suzuki T, Kato D, Kawai T, Murakami H, Hattori M. Effect of alumina content of dental zirconia on translucency and lowtemperature degradation. Aichi Gakuin Dent Sci 2015; 28: 27-35.

56) Ross IM, Rainforth WM, McComb DW, Scott AJ, Brydson R. The role of trace additions of alumina to yttria-tetragonal zirconia polycrystals (Y-TZP). Scripta Materialia 2001; 45: 653-660.

57) Wu ZK, Li N, Jian C, Zhao WQ, Yan JZ. Low temperature degradation of $\mathrm{Al}_{2} \mathrm{O}_{3}$ doped $3 \mathrm{Y}-\mathrm{TZP}$ sintered at various temperatures. Ceram Int 2013, 39: 7199-7204.

58) Shimbo M, Ueki M, Miyano Y, Ishihara S, Fujita T. Compressive strength of partially stabilized zirconia and stress-induced phase transformation. J Soc Mater Sci Jpn 1988; 37: 1043-1049.

59) Okuda Y, Noda M, Tsuruki J, Ban S. Property change of dental zirconia with contamination during final firing. Arch Bioceram Res 2010; 10: 70-73.

60) Ban S, Okuda Y, Noda M, Tsuruki J, Kawai T, Kono H. Contamination of dental zirconia before final firing: Effects on mechanical strength. Dent Mater J 2013; 32: 1011-1019.

61) Sasaki K, Hayashi T, Asakura M, Ando M, Kawai, Ban S. Improving biocompatibility of zirconia surface by incorporating Ca ions. Dent Mater J 2015; 34: 336-344.

62) Ando M, Kato D, Kawai T, Murakami H, Hattori M. Nanoscale surface treatment of zirconia using borax and hydrofluoric acid. Aichi Gakuin Dent Sci 2015; 28: 19-26.

63) Noda M, Okuda Y, Arikawa H, Kanie T, Fujii K, Ban S. Acid resistance of zirconia. J J Dent Mater 2009; 28: 114. (Abst P-49)

64) Iwata J, Uematsu Y, Tomino M, Tsuruta S, Hayashi T, Kawai $\mathrm{T}$, et al. Chemical durability of CAD/CAM dental materials. J J Dent Mater 2015; 34: 315. (Abst A-3)

65) Ban S, Iwata J, Okada R, Asakura M, Kawai T. Chemical durability of dental glass ceramics. J J Dent Mater 2016; 35 : 122. (Abst A-15)

66) Wiederhorn SM, Bolz LH. Stress corrosion and static fatigue of glass. J Am Ceram Soc 1970; 53: 543-548.

67) Michalske TA, Freiman SW. A molecular mechanism for stress corrosion in vitreous silica. J Am Ceram Soc 1983; 66: 284-288.

68) Harada A, Ban S, Matsuura M, Kato N, Watanabe K, Koyama $\mathrm{K}$, et al. Factors affecting on the flexure strength of dental porcelains. Surface finish and measurement environment. J J Dent Mater 1994; 13: 170-171.(Abst. P-35)

69) Ban S, Harada A, Hasegawa J. Effect of glazing on the biaxial flexure strength of dental porcelains. Microstructures and Mechanical Properties of New Engineering Materials, Edited by B. Xu, M. Tokuda, and J. Song, International Academic Publishers, Beijing, 1995; 3-8.

70) Hattori M, Ban S, Hasegawa J. Biaxial flexure strength Effect of test environment, J J Dent Mater 1997; 16: 109. (Abst P-38)

71) Ban S, Iwata J, Asakura M, Kawai T. Biaxial flexural strengths of pressed glass ceramics. J J Dent Mater 2017; 36: 68. (Abst A-6)

72) Ando A, Okada R, Takeichi T, Nakamura Y, Kawai T, Tanaka $\mathrm{T}$, et al. Color stability of dental milling resin for CAD/CAM crown. Aichi Gakuin Dent Sci 2014; 52: 4. (Abst 7)

73) Okada R, Ando A, Takeichi T, Nakamura Y, Tanaka T, Kawai $\mathrm{T}$, et al. Accelerated aging test for dental milling resin for CAD/CAM crown. J J Dent Mater 2015; 34: 122. (Abst A-29) 